\title{
EFEKTIVITAS PENGEMBANGAN NILAI-NILAI KARAKTER BANGSA MELALUI EKSTRAKURIKULER PRAMUKA
}

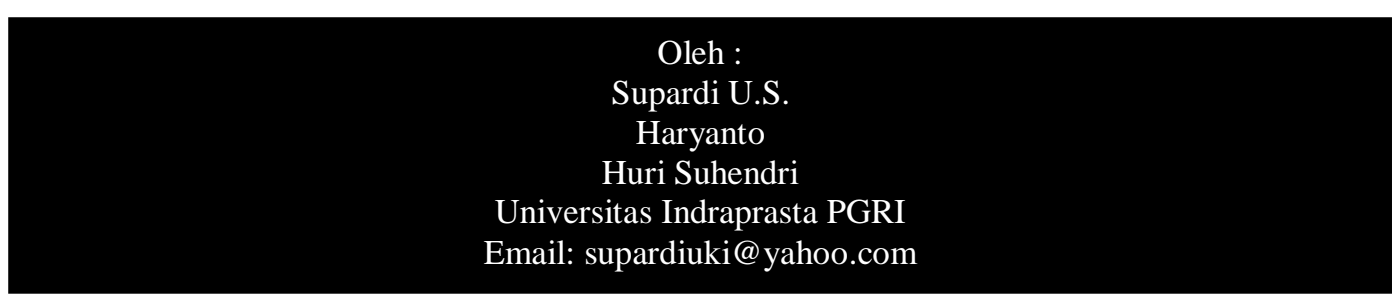

\begin{abstract}
This study aims to analyze and effectiveness of the development of the character of the nation's values (self-reliance, self-discipline, tolerance, mutual cooperation, ketahanmalangan, and creativity) through extracurricular activities scout. The research method in this study using a survey method ex post facto by using multivariate data analysis techniques of analysis of variance (MANOVA). Research respondents are students and instructors extracurricular high school level. Data collection techniques used in this study was a questionnaire (questionnaire), interviews, and documentation. In an effort to obtain research data that can be justified or legitimate, then the data keabsahannnya research first examined by cross-checking techniques. Prior to testing the hypothesis, then the first test performed data analysis requirements consist of tests of normality and homogeneity tests. The results of hypothesis testing, it is concluded that there are differences in the values of national character (self-reliance, self-discipline, tolerance, mutual cooperation, ketahanmalangan, and creativity) in terms of their organization and extracurricular activities scout. So the advice that can be given in the development of national character values (self-reliance, self-discipline, tolerance, mutual cooperation, ketahanmalangan, and creativity) can scout through extracurricular activities.
\end{abstract}

Keywords: the values of the nation's character, ektrakurikuler scout.

Abstrak. Penelitian ini bertujuan untuk menganalisis dan efektivitas pengembangan nilai-nilai karakter bangsa (kemandirian, kedisiplinan, tenggang rasa, kegotongroyongan, ketahanmalangan, dan kreativitas) melalui kegiatan ekstrakurikuler pramuka. Metode penelitian dalam penelitian ini menggunakan metode survey expost facto dengan teknik analisis data mengunakan multivariat of analaisis varians (MANOVA). Responden penelitiannya adalah siswa dan pembina ekstrakurikuler di tingkat SLTA. Teknik pengumpulan data yang digunakan dalam penelitian ini adalah angket (kuisioner), wawancara, dan dokumentasi. Dalam upaya memperoleh data penelitian yang dapat dipertanggungjawabkan atau absah, maka data penelitian terlebih dahulu diperiksa keabsahannnya dengan teknik cross check. Sebelum dilakukan pengujian hipotesis, maka dilakukan terlebih dahulu pengujian persyaratan analisis data yang terdiri dari uji normalitas dan uji homogenitas. Hasil pengujian hipotesis, maka disimpulkan bahwa terdapat perbedaan nilai-nilai karakter bangsa (kemandirian, kedisiplinan, tenggang rasa, kegotongroyongan, ketahanmalangan, dan kreativitas) ditinjau dari adanya organisasi dan kegiatan ekstrakurikuler pramuka. Sehingga dapat diberikan saran bahwa dalam pengembangan nilai-nilai karakter bangsa (kemandirian, kedisiplinan, tenggang rasa, kegotongroyongan, ketahanmalangan, dan kreativitas) dapat melalui kegiatan ekstrakurikuler pramuka.

Kata kunci: nilai-nilai karakter bangsa, ektrakurikuler pramuka.

\section{A. PENDAHULUAN}

Pendidikan nilai-nilai karakter bangsa merupakan kebutuhan yang harus tetap terjaga agar setiap generasi dapat memahami dengan baik dan mampu mengangkat citra bangsa Indonesia di mata 
bangsa lain. Apabila setiap warga negara memiliki karakter bangsa yang baik dan melaksanakan dengan baik pula, maka kehidupan bermasyarakat dan bernegara yang terjadi akan baik pula. Selain itu, karakter merupakan salah satu unsur dari jati diri selain kepribadian.

Semakin pesatnya perkembangan teknologi informasi menyebabkan semakin mudah pula seseorang dalam mengakses berbagai informasi dari dalam maupun luar negeri. Sehingga secara langsung maupun tidak langsung, informasi yang diperoleh dari kemajuan teknologi ini dapat mempengaruhi nilai-nilai kesadaran berbangsa dan bernegara seseorang. Sehingga pola hidup dan kehidupan seseorang dipengaruhi oleh budaya dari luar yang diperoleh melalui pemanfaatan teknologi informasi tersebut.

Begitu pentingnya nilai-nilai kebangsaan bagi kelangsungan hidup suatu bangsa maka setiap bangsa berusaha menanamkan rasa nasionalisme dan kebangsaan ini melalui pendidikan formal, informal, dan non formal. Bahkan pemerintah berupaya dengan menetapkan menetapkan agar mata pelajaran yang berhubungan dengan penanaman nilai-nilai karakter bangsa diajarkan pada siswa dari tingkat sekolah dasar (SD) sampai perguruan tinggi (PT).

Hal tersebut dengan mengacu pada pernyataan dalam UU nomor 20 tahun 2003 tentang Sistem Pendidikan Nasional pasal 3 yang menyebutkan bahwa "Pendidikan nasional berfungsi mengembangkan kemampuan dan membentuk karakter watak serta peradaban bangsa yang bermartabat dalam rangka mencerdaskan kehidupan bangsa, bertujuan untuk berkembangnya potensi peserta didik agar menjadi manusia yang beriman dan bertaqwa kepada Tuhan Yang Maha Esa, berakhlak mulia, sehat, berilmu, cakap, kreatif, mandiri, dan menjadi warga Negara yang demokratis dan bertanggung jawab." Artinya melalui pendidikan diharapkan setiap warga Negara khususnya peserta didik memiliki nilai-nilai karakter yang baik seperti : kreatif dan mandiri. Dengan memiliki nilai-nilai karakter yang baik, maka jati diri peserta didik akan baik pula.

Dalam kurikulum 2013 juga ditekankan bahwa pendidikan karakter kebangsaan merupakan materi yang terintegrasi dalam mata pelajarn yang disampaikan kepada peserta didik. Tujuan dari hal tersebut agar peserta didik memahami karakter bangsa Indonesia dan menyadari bahwa bangsa Indonesia memiliki ciri-ciri yang berbeda sengan bangsa lain sehingga tidak mudah menerima faham atau ajaran dari luar yang tidak sesuai dengan nilai-nilai karakter bangsa Indonesia.

Nilai-nilai karakter bangsa merupakan nilai kepribadian suatu bangsa yang mencerminkan sikap-sikap positif yang 
menjadi ciri khas dari suatu negara. Nilainilai karakter bangsa juga merupakan suatu ciri khas yang menjadi pembeda dengan yang lain. Sehingga sebuah bangsa harus memiliki karakter bangsa yang menjadi kepribadian atau jati diri setiap warga negaranya. Karakter bangsa memiliki peranan penting dalam perkembangan suatu bangsa. Sehingga pendidikan karakter perlu dikembangkan dalam dunia pendidikan khususnya dalam pembelajaran.

Usaha yang dilakukan pemerintah tidak hanya sekedar menetapkan pelajaran pendidikan karakter bangsa sebagai salah satu materi yang wajib diajarkan kepada setiap peserta didik di berbagai jenjang pendidikan. Pemerintah juga berupaya melakukan penanaman nilai-nilai karakter bangsa melalui pendidikan non formal yaitu kegiatan ekstrakurikuler yang diselenggarakan di sekolah. Kegiatan ekstrakurikuler tersebut dilaksanakan dengan tujuan untuk mendidik peserta didik agar memiliki keterampilan dan meningkatkan rasa nasionalisme yang ada pada peserta didik. Hal tersebut sesuai dengan pernyataan dalam UU nomor 20 tahun 2003 tentang Sistem Pendidikan Nasional pasal 26 ayat 2 bahwa "pendidikan non formal berfungsi mengembangkan potensi peserta didik dengan penekanan pada penguasaan pengetahuan dan keterampilan fungsional serta pengembangan sikap dan kepribadian profesional."

Kegiatan esktrakurikuler merupakan kegiatan yang dilaksanakan secara terorganisir oleh peserta didik baik di tingkat sekolah maupun perguruan tinggi di luar jam belajar kurikulum standar. Kegiatan ekstrakurikuler dilaksanakan dalam rangka pengembangan kepribadian, bakat, dan kemampuan lain di luar akademik dengan tujuan memberikan manfaat positif kepada peserta didik. Kegiatan ekstrakurikuler merupakan bagian dari pendidikan non formal. Menurut Lestari (2013) bahwa "unsur didalam pendidikan nonformal adalah pendidikan kepemudaan. Unsur yang ada di dalam pendidikan kepemudaan adalah Gerakan Pramuka."

Salah satu kegiatan ekstrakurikuler yang dilaksanakan di sekolah adalah gerakan pramuka. Melalui kegiatan pramuka peserta didik dilatih dan dibimbing masalah pengembangan keterampilan dan nilai-nilai karakter bangsa yang baik. Dalam UU nomor 12 tahun 2010 tentang Gerakan Pramuka pasal 1 ayat 1 disebutkan bahwa "gerakan pramuka adalah organisasi yang dibentuk oleh pramuka untuk menyelenggarakan pendidikan kepramukaan." Gerakan pramukan merupakan organisasi resmi yang ditetapkan baik nasional maupun internasional. Di Indonesia, gerakan pramuka dilakukan secara berjenjang 
Edutech, Tahun 13, Vol.1, No.3, Oktober 2014

mulai dari Gugus Depan di tingkat satuan pendidikan dan Kwartir di tingkat pemerintahan. Kemudian dalam UU nomor 12 tahun 2010 tentang Gerakan Pramuka pasal 20 ayat 2 dinyatakan bahwa "satuan organisasi gerakan pramuka terdiri atas : a. gugus depan, dan b. kwartir." Kemudian dalam UU nomor 12 tahun 2010 tentang Gerakan Pramuka pasal 23 bahwa "kwartir terdiri atas : a. kwartir ranting di tingkat kecamatan, b. kwartir cabang di tingkat kabupaten/ kota, c. kwartir daerah di tingkat provinsi, dan d. kwartir nasional di tingkat negara." Selain itu dalam UU nomor 12 tahun 2010 tentang Gerakan Pramuka pasal 4 dinyatakan bahwa "Gerakan pramuka bertujuan untuk membentuk setiap pramuka agar memiliki kepribadian yang beriman, bertaqwa, berakhlak mulia, berjiwa patriot, taat hukum, disiplin, menjunjung tinggi nilai luhur bangsa, dan memiliki kecakapan hidup sebagai kader bangsa dalam menjaga dan membangun Negara Kesatuan Republik Indonesia, mengamalkan Pancasila, dan melestarikan lingkungan hidup." Selain itu, menurut pendapat Irwanto \& Jatiningsih (2013:552) bahwa "pramuka merupakan salah satu kegiatan ekstrakurikuler yang ada pada jenjang pendidikan." Artinya kegiatan gerakan pramuka merupakan kegiatan yang dilaksanakan di sekolah maupun perguruan tinggi di luar jam belajar formal.
Dalam kegiatan ekstrakurikuler kepramukaan, peserta didik dilatih dan dikembangkan nilai-nilai karakter bangsa. Menurut Patimah (2011) bahwa "Secara umum nilai-nilai karakter yang tercantum dalam pembinaan kegiatan pramuka adalah percaya diri, patuh pada aturan-aturan sosial, menghargai keberagaman, berpikir logis, kritis, kreatif dan inovatif, mandiri, pemberani, bekerja keras, tekun, ulet/gigih, disiplin, visioner, bersahaja, bersemangat, dinamis, pengabdian, tertib, konstruktif." Sedangkan menurut Sudrajad (2013) bahwa "nilai-nilai kepramukaan adalah nilai-nilai positif yang diajarkan dan ditanamkan kepada para anggota pramuka. Nilai-nilai ini merupakan nilai moral yang menghiasi perilaku anggota pramuka."

Kegiatan gerakan pramuka memberikan nilai-nilai kepribadian dan karakter bangsa yang baik. Sudrajad (2013:2)

$$
\text { menyatakan bahwa }
$$

"kepramukaan adalah proses pendidikan di luar lingkungan sekolah dan keluarga dalam bentuk kegiatan menarik, menyenangkan, sehat, teratur, terarah, praktis yang dilakukan di alam terbuka dengan Prinsip Dasar Kepramukaan Metode Kepramukaan yang sasaran akhirnya pembentukan watak, akhlak, dan budi pekerti luhur."

Kegiatan pramuka tersebut dilaksanakan sebagai pemberian dasar atau bekal para peserta didik dalam menghadapi perkembangan zaman dan teknologi 
informasi yang semakin pesat. Pramuka adalah salah satu kegiatan ekstrakurikuler yang dilaksanakan mulai dari sekolah dasar (SD) sampai perguruan tinggi (PT).

Dilihat dari aktifitas kegiatan yang dilaksanakan dalam kegiatan pramuka, maka jelas terlihat adanya penanaman nilai-nilai karakter bangsa yang kuat.

Walaupun sudah merupakan ektrakurikuler yang wajib dilaksanakan oleh tiap sekolah, namum masih ada sekolah yang belum melaksanakannya. Khususnya ditingkat SMA/ SMK/ MA kegiatan esktrakurikuler pramuka masih jarang dilaksanakan. Hal ini menjadi pemikiran pihak sekolah dan instansi terkait agar mampu memberikan pemahaman dan motivasi kepada peserta didik ditingkat SMA/ SMK/ MA untuk mengikuti kegiatan ekstrakurikuler pramuka.

\section{Berdasarkan} permasalahanpermasalahan yang diuraikan di atas, maka perlu dilakukan suatu kajian dalam sebuah penelitian. Penelitian ini dengan judul "Efektivitas Pengembangan Nilai-Nilai Karakter Bangsa melalui Kegiatan Ekstrakurikuler Pramuka di Indonesia." Target subjek penelitian adalah siswa
SMA/SMK/MA di Indonesia. Dalam penelitian ini, hanya dikaji tentang perbandingan nilai karakter yang dikembangkan yaitu kemandirian, kedisiplinan, tenggang rasa, kegotongroyongan, ketahanmalangan, dan kreativitas berdasarkan keberadaan organisasi dan pelaksanaan pramuka di sekolah.

Penelitian ini dilaksanakan pada SMA/ SMK/ MA dengan target wilayahnya adalah Jawa Timur, Bangka Belitung, dan NTT. Lokasi penelitian terdiri dari : kota Pasuruan, kota Pangkal Pinang, dan kota Kupang.

Metode penelitian dalam penelitian ini menggunakan metode expost facto dengan teknik analisis data mengunakan multivariat of analysis varians (MANOVA). Dalam penelitian ini dilakukan analisa pengaruh kegiatan ekstrakurikuler pramukan terhadap tingkat nilai-nilai karakter bangsa siswa.

Desain penelitiannya dapat digambarkan seperti pada gambar di bawah ini :

\begin{tabular}{|l|l|l|l|l|l|l|l|l|l|l|l|l|l|l|l|l|l|}
\hline \multicolumn{5}{|c|}{ A1 } & \multicolumn{5}{c|}{ A2 } & \multicolumn{5}{c|}{ A3 } \\
\hline Y1 & Y2 & Y3 & Y4 & Y5 & Y6 & Y1 & Y2 & Y3 & Y4 & Y5 & Y6 & Y1 & Y2 & Y3 & Y4 & Y5 & Y6 \\
\hline
\end{tabular}

\section{Gambar 1. Desain Penelitian}


A1 = sekolah yang memiliki organisasi pramuka (gugus depan/gudep) dan melaksanakan kegiatan pramuka secara aktif atau wajib.

$\mathrm{A} 2$ = sekolah yang memiliki organisasi pramuka (gugus depan/gudep) dan melaksanakan kegiatan pramuka secara tidak wajib atau pilihan.

A3 =sekolah yang tidak memiliki organisasi pramuka (gugus depan/ gudep) dan tidak melaksanakan kegiatan pramuka.

Y1=nilai karakter kemandirian

Y2=nilai karakter kedisiplinan

Y3=nilai karakter tenggang rasa

$\mathrm{Y} 4=$ nilai karakter kegotongroyongan

Y5=nilai karakter ketahanmalangan

Y6=nilai karakter kreativitas

Setiap target wilayah penelitian yaitu provinsi yang telah ditentukan akan dipilih 3 (sekolah) tingkat SMA/ SMK/ MA secara random atau acak berdasarkan organisasi ektrakurikuler pramuka dan pelaksanaan kegiatan ekstrakurikuler pramuka. Populasi dalam penelitian ini adalah seluruh siswa SMA/SMK/MA di kota Pasuruan provinsi Jawa Timur, kota Pangkal Pinang provinsi Bangka Belitung, dan kota Kupang provinsi NTT. Sampel penelitiannya berjumlah 179 siswa, terdiri dari : 60 siswa SMA/SMK/MA kota Pasuruan provinsi Jawa Timur, 59 siswa
SMA/SMK/MA kota Pangkal Pinang provinsi Bangka Belitung, dan 60 siswa SMA/SMK/MA kota Kupang provinsi NTT.

Teknik analisa data yang digunakan dalam penelitian ini terdiri dari : analisis statistik deskriptif, uji persyaratan analisis data, dan uji hipotesis. Analisis statistik deskripti meliputi : distibusi frekuensi data, ukuran pemusatan data, ukuran penyebaran data, dan histogram. Uji persyaratan analisis data meliputi : uji normalitas dan uji homogenitas. Uji hipotesis penelitian menggunakan multivariat of analaisis varians (MANOVA).

\section{B. HASIL DAN PEMBAHASAN}

1. Deskripsi Data

Penelitian ini merupakan penelitian tahun ke-2 dari rencana 2 tahun. Dalam penelitian tahun ke-2, dilakukan pengumpulan data lapangan melalui survei dan pengamatan pada lokasi penelitian yang telah ditentukan. Pengumupulan data lapangan tahap I di Kota Pasuruan Provinsi Jawa Timur dan Kotamadya Pangkal Pinang Provinsi Bangka Belitung, sedangkan tahap II di Kota Kupang Provinsi NTT.

Pengolahan data dilakukan dengan bantuan program SPSS 16.00. Data hasil analisis statistik deskriptif seperti pada tabel di bawah ini :

Tabel 1. Ringkasan Statistik Deskriptif

\begin{tabular}{|c|c|c|c|c|c|c|}
\hline $\begin{array}{c}\text { Statisik } \\
\text { Deskriptif }\end{array}$ & kemandirian & kedisiplinan & $\begin{array}{c}\text { tenggang } \\
\text { rasa }\end{array}$ & $\begin{array}{c}\text { gotong } \\
\text { royong }\end{array}$ & $\begin{array}{c}\text { ketahan } \\
\text { malangan }\end{array}$ & kreativitas \\
\hline Mean & 102,68 & 108,33 & 105,51 & 101,54 & 105,94 & 96,23 \\
\hline
\end{tabular}

379 Efektivitas Pengembangan Nilai-Nilai Karakter Bangsa Melalui Ekstrakurikuler Pramuka 
Edutech, Tahun 13, Vol.1, No.3, Oktober 2014

\begin{tabular}{|c|c|c|c|c|c|c|}
\hline Median & 101,00 & 105,00 & 104,00 & 101,00 & 103,00 & 96,00 \\
\hline Standar Deviasi & 15,76 & 17,59 & 18,09 & 16,70 & 17,33 & 10,05 \\
\hline Varian & 248,42 & 309,27 & 327,31 & 278,73 & 300,24 & 101,08 \\
\hline
\end{tabular}

Berdasarkan tabel 1, rata-rata nilai memiliki rata-rata 105,94 (maksimalnya

karakter siswa sudah cukup baik.

150), dan karakter kreativitas (Y6)

Karakter kemandirian (Y1) memiliki memiliki rata-rata 96,23 (maksimalnya rata-rata 102,68 (maksimalnya 160), $150)$.

karakter kedisiplinan (Y2) memiliki

2. Uji Persyaratan Analisis Data

rata-rata 108,33 (maksimalnya 150),

Pengujian persyaratan analisis data

karakter tenggang rasa (Y3) memiliki terdiri dari uji normalitas dan uji rata-rata 105,51 (maksimalnya 150 ), homogenitas yang diolah dengan karakter kegotongroyongan memiliki rata-rata 101,54 (maksimalnya 150), karakter ketahanmalangan (Y4) bantuan program SPSS 16.00. Hasil pengujian normalitas data seperti pada tabel di bawah ini :

Tabel 2. Ringkasan Uji Normalitas Data One-Sample Kolmogorov-Smirnov Test

\begin{tabular}{|c|c|c|c|c|c|c|c|}
\hline & & $\begin{array}{c}\text { kemandiri } \\
\text { an }\end{array}$ & $\begin{array}{c}\text { kedisipli } \\
\text { nan }\end{array}$ & $\begin{array}{l}\text { tenggang } \\
\text { rasa }\end{array}$ & $\begin{array}{l}\text { gotong } \\
\text { royong }\end{array}$ & $\begin{array}{c}\text { ketahan } \\
\text { malangan }\end{array}$ & kreativitas \\
\hline \multicolumn{2}{|l|}{$\mathrm{N}$} & 179 & 179 & 179 & 179 & 179 & 179 \\
\hline \multirow[t]{2}{*}{ Normal Parameters ${ }^{\mathrm{a}}$} & Mean & $1.0268 \mathrm{E} 2$ & $\begin{array}{r}1.0833 \mathrm{E} \\
2\end{array}$ & $1.0551 \mathrm{E} 2$ & $1.0154 \mathrm{E} 2$ & $1.0594 \mathrm{E} 2$ & 96.2346 \\
\hline & $\begin{array}{l}\text { Std. } \\
\text { Deviation }\end{array}$ & $1.57614 \mathrm{E} 1$ & $\begin{array}{r}1.75860 \\
\mathrm{E} 1\end{array}$ & $1.80916 \mathrm{E} 1$ & $1.66953 \mathrm{E} 1$ & $1.73276 \mathrm{E} 1$ & $1.00538 \mathrm{E} 1$ \\
\hline \multirow[t]{3}{*}{ Most Extreme Differences } & Absolute & .089 & .099 & .106 & .099 & .115 & .061 \\
\hline & Positive & .089 & .099 & .106 & .099 & .115 & .061 \\
\hline & Negative & -.080 & -.082 & -.079 & -.043 & -.065 & -.043 \\
\hline Kolmogorov-Smirnov Z & & 1.194 & 1.321 & 1.424 & 1.326 & 1.534 & .813 \\
\hline Asymp. Sig. (2-tailed) & & .116 & .061 & .055 & .059 & .058 & .523 \\
\hline & & & & & & & \\
\hline
\end{tabular}

Berdasarkan tabel 2, pada pengujian sehingga dapat disimpulkan bahwa keenam Kolmogorov-Smirnov diperoleh nilai Sig. kelompok data tersebut berdistribusi > 0.05 untuk keenam kelompok data, normal.

Tabel 3. Ringkasan Uji Homogenitas Data Levene's Test of Equality of Error Variances ${ }^{\text {a }}$

\begin{tabular}{|c|c|c|c|c|}
\hline & $\mathrm{F}$ & df1 & $\mathrm{df} 2$ & Sig. \\
\hline Kemandirian & 2.346 & 2 & 176 & .099 \\
\hline Kedisiplinan & .016 & 2 & 176 & .984 \\
\hline tenggang_rasa & .523 & 2 & 176 & .594 \\
\hline Kegotongroyongan & 2.388 & 2 & 176 & .095 \\
\hline Ketahanmalangan & .981 & 2 & 176 & .377 \\
\hline Kreativitas & 2.787 & 2 & 176 & .064 \\
\hline
\end{tabular}

Tests the null hypothesis that the error variance of the dependent variable is equal across groups.

a. Design: Intercept + ekstrakurikuler_pramuka 
Berdasarkan tabel 3, pada pengujian Levene's Test diperoleh nilai Sig. > 0.05 untuk keenam kelompok data, sehingga dapat disimpulkan bahwa keenam kelompok data tersebut memiliki varian yang homogen. Berdasarkan uji normalitas dan uji homogenitas, maka direkomendasaikan uji hipotesis.
3. Uji Hipotesis

Pengujian hipotesis dengan menggunakan uji multivariat of analaisis varians (MANOVA) dengan bantuan program SPSS 16.00. Dalam pengujian MANOVA akan diuji komparasi berdasarkan kovariat. Hasil pengujian hipotesis dapat dilihat pada tabel di bawah ini :

Tabel 4. Hasil Uji MANOVA

Multivariate Tests ${ }^{\mathrm{d}}$

\begin{tabular}{|c|c|c|c|c|c|c|c|c|}
\hline Effect & & Value & $\mathrm{F}$ & $\begin{array}{c}\text { Hypot } \\
\text { hesis } \\
\text { df }\end{array}$ & Error df & Sig. & $\begin{array}{l}\text { Noncent. } \\
\text { Parameter }\end{array}$ & $\begin{array}{c}\text { Observed } \\
\text { Power }^{b}\end{array}$ \\
\hline \multirow[t]{4}{*}{ Intercept } & Pillai's Trace & .990 & $2.751 \mathrm{E} 3$ & 6.000 & 171.000 & .000 & 16507.883 & 1.000 \\
\hline & Wilks' Lambda & .010 & $2.751 \mathrm{E} 3$ & 6.000 & 171.000 & .000 & 16507.883 & 1.000 \\
\hline & Hotelling's Trace & 96.537 & $2.751 \mathrm{E} 3$ & 6.000 & 171.000 & .000 & 16507.883 & 1.000 \\
\hline & Roy's Largest Root & 96.537 & $2.751 \mathrm{E} 3$ & 6.000 & 171.000 & .000 & 16507.883 & 1.000 \\
\hline \multirow{4}{*}{$\begin{array}{l}\text { ekstrakurikuler_ } \\
\text { pramuka }\end{array}$} & Pillai's Trace & .185 & 2.918 & 12.000 & 344.000 & .001 & 35.015 & .990 \\
\hline & Wilks' Lambda & .822 & $2.940^{\mathrm{a}}$ & 12.000 & 342.000 & .001 & 35.284 & .990 \\
\hline & Hotelling's Trace & .209 & 2.962 & 12.000 & 340.000 & .001 & 35.548 & .991 \\
\hline & Roy's Largest Root & .160 & $4.582^{c}$ & 6.000 & 172.000 & .000 & 27.490 & .986 \\
\hline
\end{tabular}

a. Exact statistic

b. Computed using alpha $=, 05$

c. The statistic is an upper bound on $\mathrm{F}$ that yields a lower bound on the significance level.

d. Design: Intercept + ekstrakurikuler_pramuka

Tabel 5. Hasil Uji Lanjut MANOVA

Tests of Between-Subjects Effects

\begin{tabular}{|c|c|c|c|c|c|c|c|c|}
\hline Source & Dependent Variable & $\begin{array}{l}\text { Type III } \\
\text { Sum of } \\
\text { Squares }\end{array}$ & $\mathrm{df}$ & $\begin{array}{l}\text { Mean } \\
\text { Square }\end{array}$ & $\mathrm{F}$ & Sig. & $\begin{array}{l}\text { Noncent. } \\
\text { Parameter }\end{array}$ & $\begin{array}{c}\text { Observed } \\
\text { Power }^{\mathrm{b}}\end{array}$ \\
\hline \multirow[t]{6}{*}{$\begin{array}{l}\text { Corrected } \\
\text { Model }\end{array}$} & Kemandirian & $3950.610^{\mathrm{a}}$ & 2 & $\begin{array}{r}1975.30 \\
5\end{array}$ & 8.261 & .000 & 16.522 & .959 \\
\hline & Kedisiplinan & $5378.179^{c}$ & 2 & $\begin{array}{r}2689.09 \\
0\end{array}$ & 9.165 & .000 & 18.331 & .975 \\
\hline & tenggang_rasa & $2960.600^{d}$ & 2 & $\begin{array}{r}1480.30 \\
0\end{array}$ & 4.436 & .013 & 8.872 & .757 \\
\hline & kegotongroyongan & $1193.614^{\mathrm{e}}$ & 2 & 596.807 & 2.115 & .124 & 4.229 & .430 \\
\hline & Ketahanmalangan & $3447.993^{f}$ & 2 & $\begin{array}{r}1723.99 \\
6\end{array}$ & 5.856 & .003 & 11.712 & .869 \\
\hline & Kreativitas & $319.671^{\mathrm{g}}$ & 2 & 159.835 & 1.521 & .221 & 3.041 & .321 \\
\hline
\end{tabular}

381 Efektivitas Pengembangan Nilai-Nilai Karakter Bangsa Melalui Ekstrakurikuler Pramuka 
Edutech, Tahun 13, Vol.1, No.3, Oktober 2014

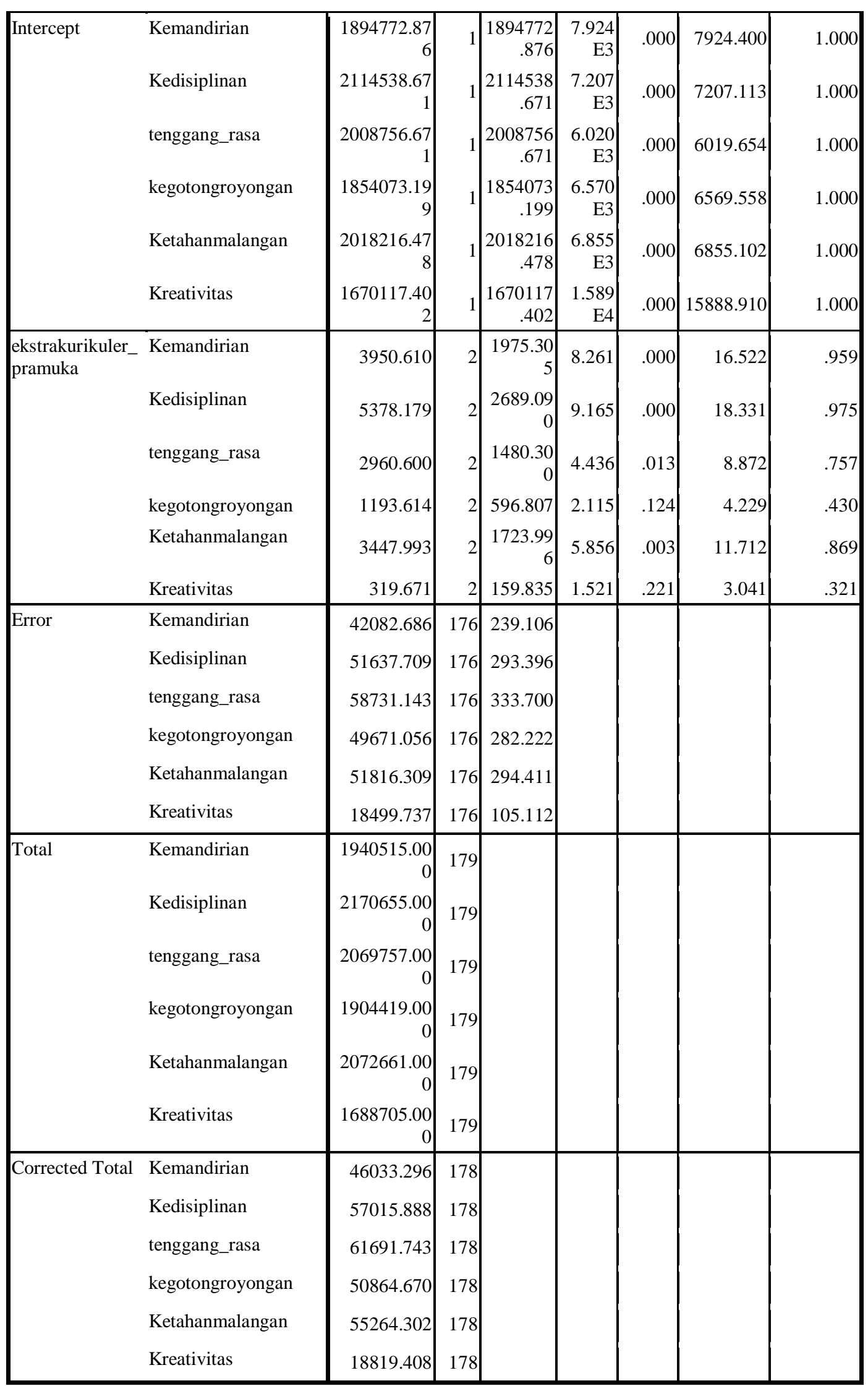

a. R Squared $=, 086$ (Adjusted R Squared $=, 075)$ 
b. Computed using alpha $=, 05$

c. R Squared $=, 094$ (Adjusted R Squared $=, 084$ )

d. R Squared $=, 048$ (Adjusted R Squared $=, 037$ )

e. $\mathrm{R}$ Squared $=, 023$ (Adjusted R Squared $=, 012$ )

f. R Squared $=, 062$ (Adjusted R Squared $=, 052)$

g. R Squared $=, 017$ (Adjusted R Squared $=, 006$ )

Berdasarkan tabel 4, pada pengujian Pillai's Trace, Wilks' Lambda, Hotelling's Trace, dan Roy's Largest Root diperoleh nilai Sig. < 0.05, sehingga dapat disimpulkan bahwa terdapat perbedaan nilai-nilai karakter Y1, Y2, Y3, Y4, Y5, dan Y6 berdasarkan A. Artinya terdapat perbedaan karakter kemandirian, kedisiplinan, tenggang rasa, kegotongroyongan, ketahanmalangan, dan kreativitas berdasarkan pengelompokkan kegiatan ekstrakurikuler pramuka.

4. Pembahasan

Berdasarkan hasil pengujian hipotesis dengan uji multivariat of analaisis varians (MANOVA) diperoleh perbedaan nilai-nilai karakter (kemandirian, kedisiplinan, tenggang rasa, kegotongroyongan, ketahanmalangan, dan kreativitas) siswa berdasarkan pengelompokkan organisasi pramuka dan pelaksanaan kegiatan pramuka. Sekolah dikelompokkan menjadi (1) memiliki organisasi pramuka (gugus depan) dan melaksanakan kegiatan pramuka secara wajib, (2) memiliki organisasi pramuka (gugus depan) dan melaksanakan kegiatan pramuka secara pilihan, dan (3) tidak memiliki organisasi pramuka (gugus depan) dan tidak melaksanakan kegiatan pramuka.

Kegiatan pramuka merupakan salah satu ekstrakurikuler yang dilaksanakan di sekolah. Hal ini sesuai dengan pendapat Irwanto \& Jatiningsih (2013:552) bahwa "pramuka merupakan salah satu kegiatan ekstrakurikuler yang ada pada jenjang pendidikan." Artinya kegiatan gerakan pramuka merupakan kegiatan yang dilaksanakan di sekolah maupun perguruan tinggi di luar jam belajar formal. Selain itu, kegiatan pramuka merupakan salah satu upaya dalam mengembangkan nilai-nilai karakter bangsa. Sudrajad (2013:2) menyatakan bahwa "kepramukaan adalah proses pendidikan di luar lingkungan sekolah dan keluarga dalam bentuk kegiatan menarik, menyenangkan, sehat, teratur, terarah, praktis yang dilakukan di alam terbuka dengan Prinsip Dasar Kepramukaan Metode Kepramukaan yang sasaran akhirnya pembentukan watak, akhlak, dan budi pekerti luhur."

Sehingga kegiatan pramuka sangat memberikan manfaat positif. Oleh 
Edutech, Tahun 13, Vol.1, No.3, Oktober 2014

karena itu perlu didukung dan dikembangkan lagi khususnya metode pelatihannya sehingga siswa lebih tertarik mengikuti pramuka. Dalam kurikulum 2013 lebih menekankan pada pembentukkan karakter siswa. Pemerintah pula telah menetapkan pramuka merupakan kegiatan ekstrakurikuler yang harus dilaksanakan di setiap sekolah. Hal ini sesuai dengan UU nomor 12 tahun 2010 tentang Gerakan Pramuka pasal 8 dinyatakan bahwa "Nilai kepramukaan mencakup : a. keimanan dan ketaqwaan kepada Tuhan Yang Maha Esa, b. kecintaan pada alam dan sesama manusia, c. kecintaan pada tanah air dan bangsa, d. kedisiplinan, keberanian, dan kesetiaan, e. tolong menolong, f. jernih dalam berpikir, berkata, dan berbuat, g. hemat, cermat, dan bersahaja, h. rajin dan terampil." Nilainilai tersebut sangat penting dimiliki oleh semua warga negara Indonesia khususnya peserta didik dalam menghadapi perkembangan ilmu pengetahuan dan teknologi informasi. Sehingga peserta didik mampu memilah informasi dan pengetahuan yang diperoleh dari pemanfaatan teknologi informasi sehingga kepribadiannya tetap memiliki jiwa nasionalisme dan kepribadian yang baik.

\section{SIMPULAN}

1. Kesimpulan
Berdasarkan hasil pengujian hipotesis penelitian, maka dapat disimpulkan bahwa terdapat pengaruh kegiatan ekstrakurikuler pramuka terhadap nilai-nilai karakter bangsa (kemandirian, kedisiplinan, tenggang rasa, kegotongroyongan, ketahan malangan, dan kreativitas) berdasarkan pengelompokkan : organisasi (gugus depan/ gudep) dan kegiatan pramuka. Artinya nilai karakter bangsa siswa yang sekolahnya memiliki organisasi (gudep) dan kegiatan pramukanya bersifat wajib berbeda dengan nilai karakter bangsa siswa yang sekolahnya memiliki organisasi (gudep) dan kegiatan pramukanya bersifat pilihan serta nilai karakter bangsa siswa yang sekolahnya tidak memiliki organisasi (gudep) dan tidak kegiatan pramuka.

2. Saran

Berdasarkan hasil penelitian dan simpulkan, maka peneliti memberikan beberapa saran, yaitu :

a. Dinas pendidikan baik tingkat provinsi maupun kabupaten/ kota agar memberikan kebijakan tentang perlunya setiap sekolah memiliki organisasi pramuka (gudep) dan pelaksanan kegiatan pramuka diwajibkan atau minimal menjadi piihan.

b. Sekolah agar memfasilitasi dan mendorong agar kegiatan pramuka 
Edutech, Tahun 13, Vol.1, No.3, Oktober 2014

di sekolahnya berjalan aktif dan memiliki gudep.

c. Siswa agar mengikuti kegiatan pramuka sebab dalam kegiatan pramuka dilatih dan diajarkan tentang pengembangan karakterkarakter bangsa.

\section{DAFTAR PUSTAKA}

Irwanto, A.C. \& Jatiningsih, O. (2013). Peranan Kegiatan Ekstrakurikuler Pramuka dalam Membentuk Kedisiplinan Siswa di SMP N 1 Sugio Kabupaten Lamongan. Jurnal kajian Moral dan Kewarganegaraan, Vol. 3 (1) : 549-563.

Lestari, L.R. (2013). Pendidikan Karakter melalui Kepramukaan.

http://www.bppnfi-

reg4.net/web/index.php/pendidikankarakter-melalui-kepramukaan.html. diunduh tanggal 2-12-2013.

Patimah. (2011). Pendidikan Karakter melalui Program Ekstrakurikuler. http://skp.unair.ac.id/repository/Gur $\underline{\mathrm{u}-}$

Indonesia/PENDIDIKANKARAKT

ER_PATIMAH_16759.pdf.html. diakses tanggal 2-12-2013.

Sudrajad, J. (2013). Hubungan Nilai-Nilai Kepramukaan, Karakter Disiplin, dan Kerja Keras terhadap Prestasi Belajar Siswa Mata Pelajaran Produktif di SMK PGRI 1 Ngawi. http://eprints.uny.ac.id/10059/1/jurn al\%20penelitian. diunduh tanggal 212-2013. - (2010). Undang-Undang RI Nomor 12 Tahun 2010 Tentang Gerakan

Pramuka.http://ditjenpas.go.id/sites/ default/files/UU\%20NO\%2012\%20 TAHUN\%202010\%20GERAKAN\% 20PRAMUKA.pdf. diunduh tanggal 2-12-2013. 